\title{
Measuring Micro-amp Inductor Currents in Switched-inductor DC-DC Power Supplies
}

\author{
Andrés A. Blanco, Graduate Student Member, IEEE, and Gabriel A. Rincón-Mora, Fellow, IEEE \\ Georgia Institute of Technology, Atlanta, Georgia 30332 U.S.A. \\ E-mail: ablanco@gatech.edu and Rincon-Mora@gatech.edu
}

\begin{abstract}
Wireless microsystems can add performanceenhancing, energy-saving, and networked intelligence to inaccessible places like the human body and large infrastructures like factories, hospitals, and farms. For this, they require an onboard source and a power-conditioning circuit that supply microwatts about a prescribed dc voltage. And since tiny dc batteries store little energy, switched-inductor dc-de converters are popular in this respect, because they dissipate less power than linear regulators and are more accurate than switched capacitors. To monitor how they operate and ultimately meet these expectations, engineers monitor the current flowing through the inductor. In the case of miniaturized supplies, however, inductors switch at $100 \mathrm{kHz}-1 \mathrm{MHz}$ to produce microamp currents that are difficult to sense. Although series resistors and magnetically coupled probes are normally viable options, the series components they introduce into the conduction path alter the currents being measured and noise energy obscures the results. But as experimental measurements further show, characterizing and extracting current from the terminal voltages of the inductor is less obtrusive and less sensitive to noise.
\end{abstract}

Keywords-Switched inductor, switching dc-dc converter, current measurement, microsupply, microsystem, microwatt.

\section{SUPPLYING MiCROSYSTEMS}

Wireless microsystems in inaccessible places like the human body and large infrastructures like factories, hospitals, and farms can monitor, process, and transmit information that can save lives and energy and, generally, improve performance [1-2]. Since the sensors, analog-digital (A/D) converters, digital-signal processors (DSP), and transmitters they incorporate from Fig. 1 demand power to operate, these tiny contraptions also include energy sources and power-supply circuits. The latter are usually switched inductors because small batteries cannot afford to lose the power that linear regulators consume and analog functions cannot survive the ripples that switched on-chip capacitors produce [3].

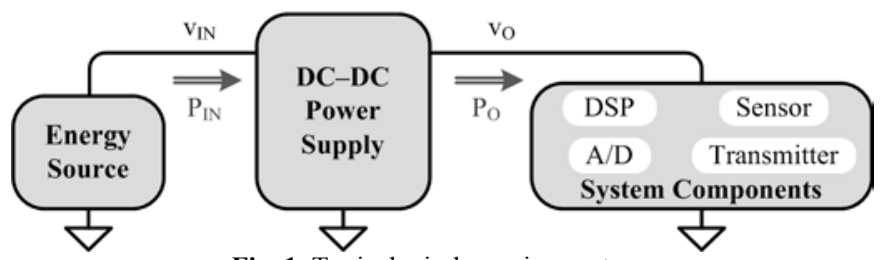

Fig. 1. Typical wireless microsystem.

Interestingly, inductor current $\mathrm{i}_{\mathrm{L}}$ dictates several key performance parameters in switching dc-dc converters [4-7]. For one, $\mathrm{i}_{\mathrm{L}}$ defines how much power the system draws from the input $\mathrm{v}_{\mathrm{IN}}$ as $\mathrm{P}_{\mathrm{IN}}$ and outputs to $\mathrm{v}_{\mathrm{O}}$ as $\mathrm{P}_{\mathrm{O}}$. $\mathrm{i}_{\mathrm{L}}$ also determines the power that components in the conduction path consume. Plus, $i_{L}$ 's waveform establishes the ripple voltage that appears across the load in $v_{O}$. This is why monitoring $i_{L}$ is critical when evaluating switched-inductor supplies [8-10].

Unfortunately, current levels in miniaturized systems are so low at micro-amps that discerning them in the presence of switching and thermal noise is challenging. And inserting current sensors introduce voltage drops that alter how these currents behave. For more details on this, Section II describes the operation of switched-inductor supplies and the effects of series resistances on $\mathrm{i}_{\mathrm{L}}$. Afterwards, Sections III $-\mathrm{V}$ evaluate to what extent magnetically coupled probes, series resistors, and current extractors can reconstruct $i_{L}$. Sections VI and VII then compare results and draw relevant conclusions.

\section{SWITCHED-INDUCTOR MiCROSUPPLIES}

\section{A. Operation}

Switched-inductor dc-dc supplies draw and supply energy from the input $\mathrm{v}_{\mathrm{IN}}$ to the output $\mathrm{v}_{\mathrm{O}}$ in alternate cycles of a switching period $t_{S W}$. For this, switches $S_{I}$ and $S_{E}$ in Fig. 2 close to energize inductor $\mathrm{L}_{\mathrm{X}}$ from $\mathrm{v}_{\mathrm{IN}}$. With a constant positive energizing voltage $v_{E}, L_{X}$ 's voltage $v_{L}$ or $L_{X} d_{L} / d t$ is constant and $i_{L}$ in Fig. 3 rises and peaks to $i_{L(P K)}$ at the end of energizing time $t_{E}$. $S_{I}$ and $S_{E}$ then open and $S_{D}$ and $S_{O}$ engage to impress a constant negative voltage $v_{D}$ across $L_{X}$ that drains $\mathrm{L}_{\mathrm{X}}$ into $\mathrm{v}_{\mathrm{O}}$. $\mathrm{i}_{\mathrm{L}}$, as a result, falls from $\mathrm{i}_{\mathrm{L}(\mathrm{PK})}$ until $\mathrm{L}_{\mathrm{X}}$ depletes after $t_{D}$. At this point, when $i_{L}$ is zero, the system opens $S_{O}$ and repeats the sequence at the onset of the next switching cycle.

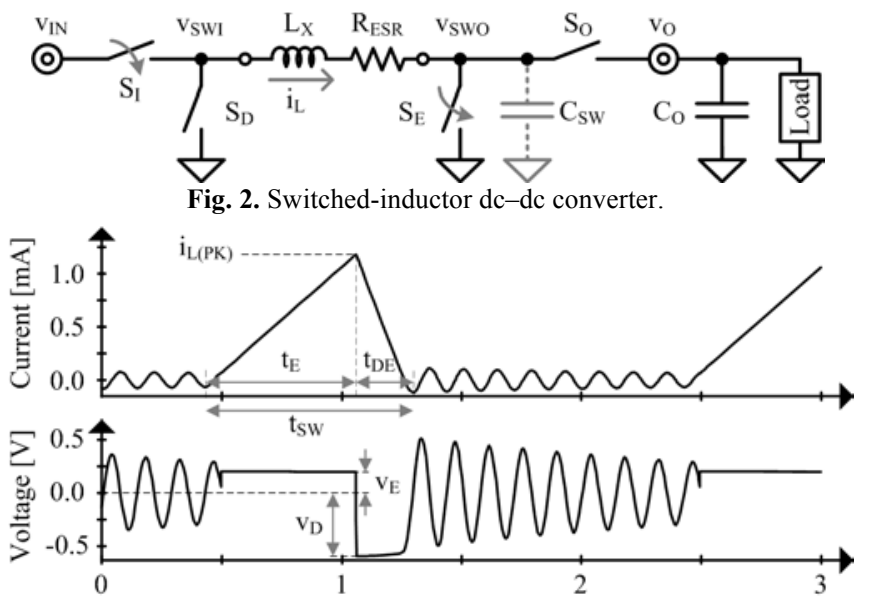

Fig. 3. Measured inductor current and voltage across time. 
Power levels are so low in microsystems that $i_{L(P K)}$ is usually not high enough to keep $\mathrm{L}_{\mathrm{X}}$ conducting across all of $t_{\text {SW }}$. Notwithstanding, since the parasitic capacitance $\mathrm{C}_{\mathrm{SW}}$ at the switching node $v_{S w O}$ near $v_{O}$ is close to $v_{O}$ after $S_{O}$ opens, $\mathrm{C}_{\mathrm{SW}}$ stores charge that $\mathrm{L}_{\mathrm{X}}$ draws and returns to $\mathrm{C}_{\mathrm{SW}}$ to produce the oscillations in Fig. 3. These oscillations fade with time because parasitic resistance gradually dissipates the energy.

The physical size of $\mathrm{L}_{\mathrm{X}}$ in miniaturized systems is so low that reasonable inductances include Ohms of equivalent series resistance $R_{E S R}$. This means $v_{E}$ and $v_{D}$ appear across both $L_{X}$ and $\mathrm{R}_{\mathrm{ESR}}$, so the voltage across the inductance is not constant:

$$
\mathrm{v}_{\mathrm{L}}=\mathrm{L}_{\mathrm{X}}\left(\frac{\mathrm{di}_{\mathrm{L}}}{\mathrm{dt}}\right)+\mathrm{i}_{\mathrm{L}} \mathrm{R}_{\mathrm{ESR}} .
$$

In other words, $\mathrm{i}_{\mathrm{L}}$ is not perfectly linear:

$$
\mathrm{i}_{\mathrm{L}}=\left(\frac{\mathrm{V}_{\mathrm{L}}}{\mathrm{R}_{\mathrm{ESR}}}\right)\left[1-\mathrm{e}^{-\left(\frac{\mathrm{R}_{\mathrm{ESR}}}{\mathrm{L}_{\mathrm{X}}}\right) \mathrm{t}}\right] \approx\left(\frac{\mathrm{V}_{\mathrm{L}}}{\mathrm{R}_{\mathrm{ESR}}}\right) \mathrm{t} .
$$

Still, $v_{L}$ is usually in volts and $R_{E S R}$ 's $v_{E S R}$ in millivolts, so $i_{L}$ is nearly linear. Incidentally, $S_{O}$ can remain closed when $v_{I N}$ is always higher than $v_{O}$ because $v_{L}$ is positive from $v_{I N}$ to $v_{O}$ and negative from ground to $\mathrm{v}_{\mathrm{O}}$. Similarly, $\mathrm{S}_{\mathrm{I}}$ can remain closed when $v_{O}$ is always greater than $v_{I N}$ because $v_{L}$ is positive from $\mathrm{v}_{\mathrm{IN}}$ to ground and negative from $\mathrm{v}_{\mathrm{IN}}$ to $\mathrm{v}_{\mathrm{O}}$.

\section{B. Measuring Inductor Current}

A fundamental challenge when measuring $i_{L}$ in microsystems is discerning micro-amps from noise $i_{\mathrm{N}}$ at $100 \mathrm{kHz}-1 \mathrm{MHz}$. In other words, signal-to-noise ratio SNR can be low:

$$
\mathrm{SNR} \equiv \frac{\mathrm{i}_{\mathrm{L}}}{\mathrm{i}_{\mathrm{N}}} .
$$

Another difficulty is that inserting a series resistance $R_{S}$ distorts $i_{L}$, which means the measurement can alter $i_{L}$ :

$$
\mathrm{i}_{\mathrm{L}}^{\prime}=\left(\frac{\mathrm{v}_{\mathrm{L}}}{\mathrm{R}_{\mathrm{ESR}}+\mathrm{R}_{\mathrm{S}}}\right)\left[1-\mathrm{e}^{-\left(\frac{\mathrm{R}_{\mathrm{ESR}}+\mathrm{R}_{\mathrm{S}}}{\mathrm{L}_{\mathrm{X}}}\right) \mathrm{t}}\right] \text {, }
$$

and produce an error $i_{E}$ in Fig. 4 that rises with $R_{S}$ :

$$
\mathrm{i}_{\mathrm{E}}=\mathrm{i}_{\mathrm{L}}-\mathrm{i}_{\mathrm{L}}{ }^{\prime} \text {. }
$$

When $R_{S}$ is so high that $R_{S}$ 's voltage $v_{S}$ overwhelms $v_{L}, i_{L}{ }^{\prime}$ stops rippling and reduces to $\mathrm{v}_{\mathrm{L}} / \mathrm{R}_{\mathrm{S}}$, at which point the error $\mathrm{i}_{\mathrm{E}} / \mathrm{i}_{\mathrm{L}}$ is $100 \%$. Before that, though, when $\mathrm{L}_{\mathrm{X}}, \mathrm{R}_{\mathrm{ESR}}$, and $\mathrm{R}_{\mathrm{S}}$ are $100 \mu \mathrm{H}, 10.5 \Omega$, and $19.1 \Omega$, the error is $5 \%$ after $0.55 \mu \mathrm{s}$.

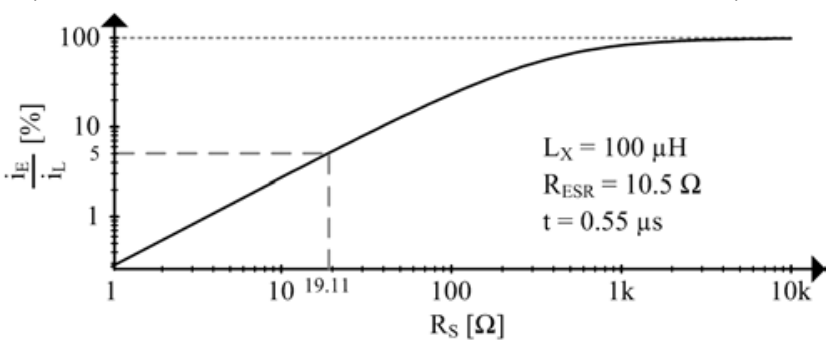

Fig. 4. Measured inductor-current error across series resistances.

\section{Magnetically Coupled PROBE}

One way to measure high-speed currents with micro-amp resolution is to use a magnetically coupled probe like Fig. 5 illustrates. This way, $i_{L}$ flows through the primary coil $L_{P}$ and current variations $\Delta \mathrm{i}_{\mathrm{L}}$ couple to the secondary coil $\mathrm{L}_{\mathrm{S}}$. $\mathrm{L}_{\mathrm{S}}$ therefore produces a voltage across $L_{S}$ 's parallel resistance $R_{P}$ that is proportional to $\Delta \mathrm{i}_{\mathrm{L}}$ and the probe's turns ratio $\mathrm{N}_{\mathrm{S}} / \mathrm{N}_{\mathrm{P}}$. So, amplifying this voltage with $\mathrm{A}_{\mathrm{V}}$ and dividing the result by $\mathrm{R}_{\mathrm{S}}$ reconstructs $\Delta \mathrm{i}_{\mathrm{L}}$ in $\mathrm{i}_{\mathrm{S}}$, as Fig. 6 shows.

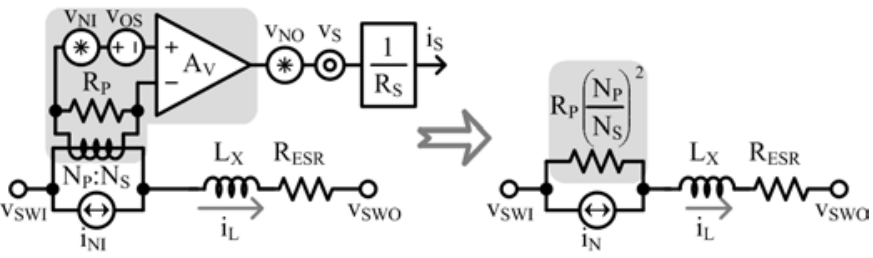

Fig. 5. Magnetically coupled probe network and equivalent primary circuit.

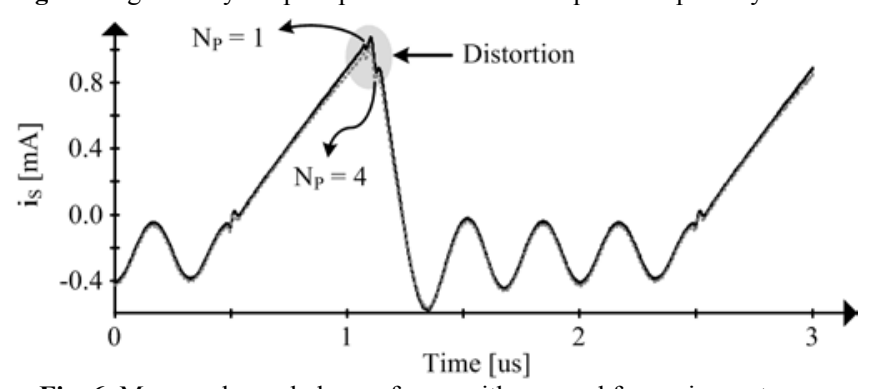

Fig. 6. Measured coupled waveforms with one and four primary turns.

In this setup, noise energy is present at the primary $i_{\mathrm{NI}}$ and at the input $\mathrm{v}_{\mathrm{NI}}$ and output $\mathrm{v}_{\mathrm{NO}}$ of $\mathrm{A}_{\mathrm{V}}$. As a result, $\mathrm{i}_{\mathrm{NI}}$ appears in $i_{L}$ and $N_{S} / N_{P}$ and $A_{V}$ reflect impressions of $v_{N O}$ and $v_{N I}$ to establish a noise current $i_{N}$ in $i_{L}$ that is equivalent to

$$
\mathrm{i}_{\mathrm{N}}=\sqrt{\mathrm{i}_{\mathrm{NI}}^{2}+\left[\left(\frac{\mathrm{v}_{\mathrm{NI}}}{\mathrm{R}_{\mathrm{P}}}\right)\left(\frac{\mathrm{N}_{\mathrm{P}}}{\mathrm{N}_{\mathrm{S}}}\right)\right]^{2}+\left[\left(\frac{\mathrm{v}_{\mathrm{NO}}}{\mathrm{A}_{\mathrm{V}} \mathrm{R}_{\mathrm{P}}}\right)\left(\frac{\mathrm{N}_{\mathrm{P}}}{\mathrm{N}_{\mathrm{S}}}\right)\right]^{2}} \approx \mathrm{i}_{\mathrm{NI}} .
$$

But since $\mathrm{N}_{S} / \mathrm{N}_{\mathrm{P}}, \mathrm{R}_{\mathrm{S}}$, and $\mathrm{A}_{\mathrm{V}}$ amplify $\mathrm{i}_{\mathrm{L}}$ and $\mathrm{i}_{\mathrm{NI}}$ in $\mathrm{i}_{\mathrm{S}}, \mathrm{i}_{\mathrm{NI}}$ dominates and $\mathrm{v}_{\mathrm{NI}}$ and $\mathrm{v}_{\mathrm{NO}}$ 's impact is low when $\mathrm{N}_{\mathrm{S}} / \mathrm{N}_{\mathrm{P}}$ is high.

Unfortunately, $N_{P} / N_{S}$ also reflects $R_{P}$ on the primary as $R_{S}$ or $R_{P}\left(N_{P} / N_{S}\right)^{2}$, which means $R_{P}$ distorts $i_{L}$. This is why $i_{L}{ }^{\prime} s$ peak in Fig. 6 is lower when $N_{P}$ is four and the measurement error in Fig. 7 rises with $N_{P}$. In other words, fewer turns in the primary reduces noise and improves linearity.

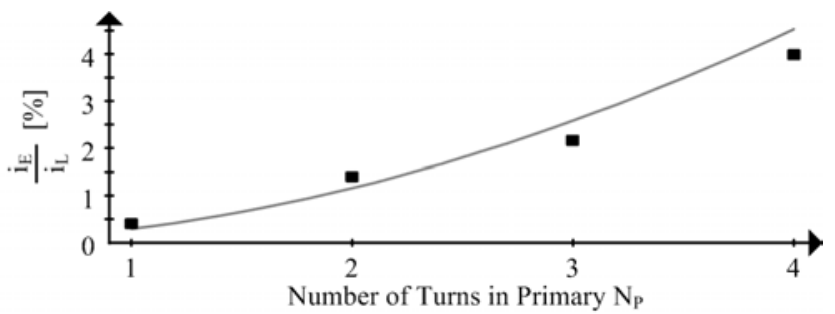

Fig. 7. Measured inductor-current error across turns in the primary coil.

Note $\mathrm{L}_{\mathrm{P}}$ only couples $\mathrm{L}_{\mathrm{X}}$ 's ripple $\Delta \mathrm{i}_{\mathrm{L}}$ to $\mathrm{L}_{\mathrm{S}}$. In other words, $i_{S}$ cannot monitor $i_{L}$ 's low-frequency components and the effects of $A_{V}$ 's offset $v_{O S}$ are negligible. Although amplifying $\mathrm{i}_{\mathrm{S}}$ at low frequency extends this method's effective bandwidth [11], magnetic coupling attenuates $i_{L}$ at low frequencies so much that $v_{\mathrm{NI}}$ overwhelms $L_{S}$ 's impression of $i_{L}$ in $R_{P}$. 


\section{SERIES SENSE RESISTOR}

Inserting a series resistor $\mathrm{R}_{\mathrm{S}}$ [12] like Fig. 8 shows is another way of monitoring $i_{L}$. Since $R_{S}$ distorts $i_{L}$, however, $R_{S}$ must be low, and in consequence, so is $R_{S}$ 's voltage $v_{S}$. This is why $A_{V}$ amplifies $v_{S}$ in Fig. 8. But since $A_{V}$ also magnifies input noise $i_{N I} R_{S}$ and $v_{N I}$, LPF attenuates frequency components of $i_{L}$ that are well above the dc-dc converter's switching frequency $\mathrm{f}_{\mathrm{SW}}$. This way, dividing LPF's filtered impression of $A_{V}$ 's output by $R_{S}$ reproduces $i_{L}$ in $i_{S}$, as Fig. 9 demonstrates.

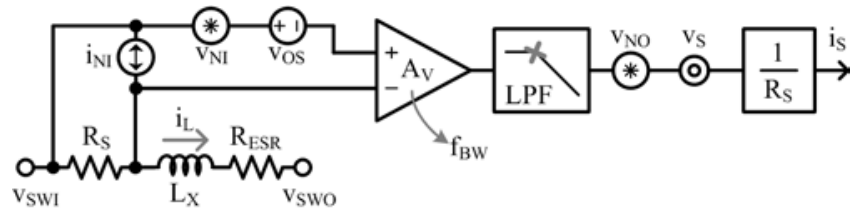

Fig. 8. Series sense-resistor network.

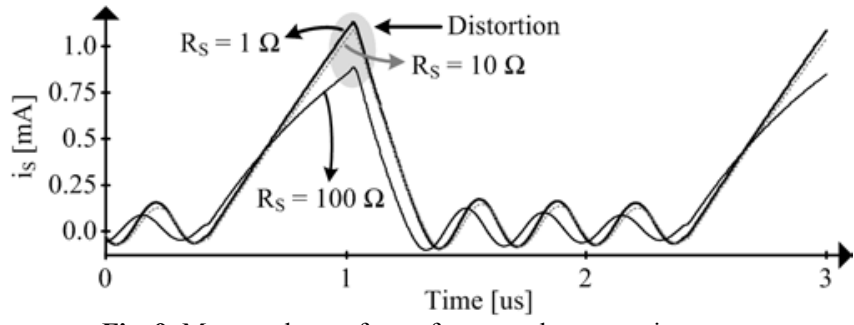

Fig. 9. Measured waveforms for several sense resistances.

Like before, noise current and voltage $i_{\mathrm{NI}}$ and $\mathrm{v}_{\mathrm{NI}}$ are present at $A_{V}$ 's input and noise voltage $v_{N O}$ at $A_{V}$ 's output. As a result, $i_{N I}$ appears in $i_{L}$ and $R_{S}$ and $A_{V}$ reflect impressions of $\mathrm{v}_{\mathrm{NO}}$ and $\mathrm{v}_{\mathrm{NI}}$ to establish a noise current $\mathrm{i}_{\mathrm{N}}$ in $\mathrm{i}_{\mathrm{L}}$ :

$$
\mathrm{i}_{\mathrm{N}}=\sqrt{\mathrm{i}_{\mathrm{NI}}{ }^{2}+\left(\frac{\mathrm{v}_{\mathrm{NI}}}{\mathrm{R}_{\mathrm{S}}}\right)^{2}+\left(\frac{\mathrm{v}_{\mathrm{NO}}}{\mathrm{A}_{\mathrm{V}} \mathrm{R}_{\mathrm{S}}}\right)^{2}} \approx \sqrt{\mathrm{i}_{\mathrm{NI}}{ }^{2}+\left(\frac{\mathrm{v}_{\mathrm{NI}}}{\mathrm{R}_{\mathrm{S}}}\right)^{2}} .
$$

But since $\mathrm{R}_{\mathrm{S}}$ and $\mathrm{A}_{\mathrm{V}}$ amplify $\mathrm{i}_{\mathrm{L}}, \mathrm{i}_{\mathrm{NI}}$, and $\mathrm{v}_{\mathrm{NI}}$ in $\mathrm{i}_{\mathrm{S}}$, $\mathrm{i}_{\mathrm{NI}}$ and $\mathrm{v}_{\mathrm{NI}}$ dominate and, when $R_{S}$ and $A_{V}$ are high, $v_{N O}$ 's impact on $i_{S}$ in Fig. 10 is low and signal-to-noise ratio SNR in Fig. 11 is high. At some point, though, $R_{S}$ amplifies $i_{N I}$ to the extent $i_{N I} R_{S}$ overwhelms $\mathrm{v}_{\mathrm{NI}}$, so $\mathrm{i}_{\mathrm{NI}}$ dominates $\mathrm{i}_{\mathrm{N}}$ and $\mathrm{i}_{\mathrm{N}}$ becomes insensitive to $R_{S}$. This is why SNR flattens at roughly $60 \mathrm{~dB}$ when $R_{S}$ is $60 \Omega$ or higher. In practice, gain $A_{V}$ and bandwidth $\mathrm{f}_{\mathrm{BW}}$ in amplifiers are conflicting parameters, so $\mathrm{f}_{\mathrm{BW}}$ should exceed $\mathrm{f}_{\mathrm{SW}}$ by $5 \times$ or $10 \times$, but not by more for $\mathrm{A}_{\mathrm{V}}$ to stay high.

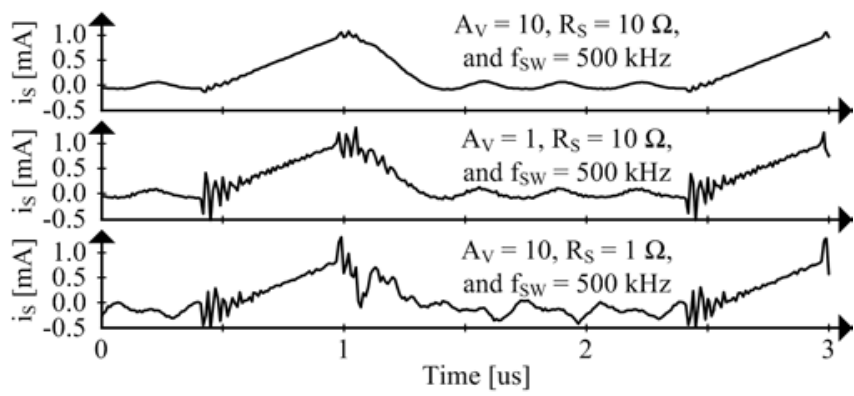

Fig. 10. Measured waveforms for several resistances and amplifier gains.

Like before, $R_{S}$ distorts $i_{L}$. This is why higher resistances lower $i_{L}$ 's peak $i_{L(P K)}$ in Fig. 9 and raise the error $i_{E} / i_{L}$ in Fig. 12. In other words, distortion offsets the benefits of lower noise when raising $R_{S}$. $R_{S}$ should therefore be high, but only to the point the error is, for example, less than $5 \%$, which in this case happens at $10 \Omega$. Note that calibrating the offset that $A_{V}$ 's $\mathrm{v}_{\mathrm{OS}}$ in Fig. 8 produces in $\mathrm{i}_{\mathrm{S}}$ is part of the measurement process.

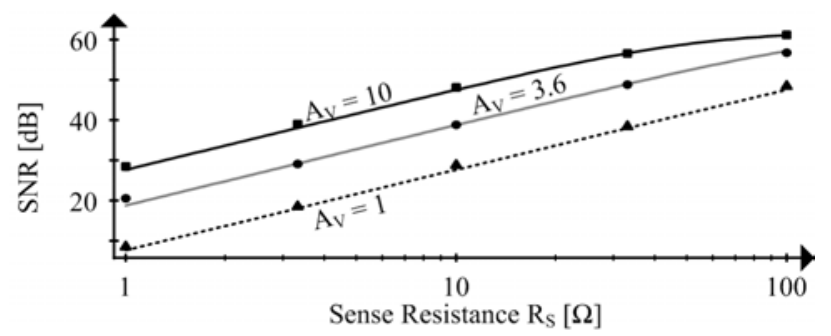

Fig. 11. Measured signal-to-noise ratio across resistances and amplifier gains.

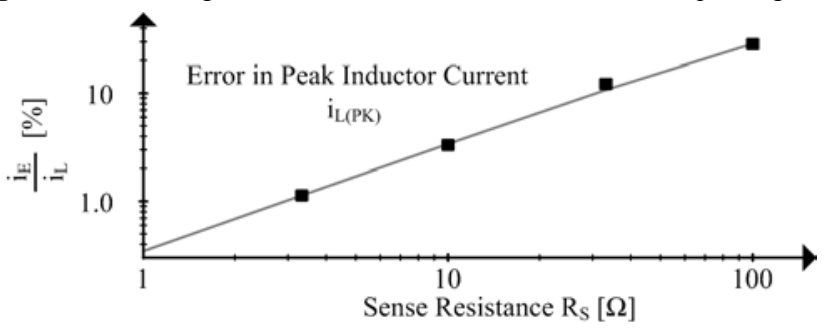

Fig. 12. Measured inductor-current error across sense resistances.

\section{CURRENT EXTRACTOR}

Another way of measuring $i_{L}$ is to extract $i_{L}$ from $L_{X}$ 's terminal voltage $v_{L}$ [13-14]. Here, the first step is to measure $L_{X}$ 's inductance and series resistance $\mathrm{R}_{\mathrm{ESR}}$. With this information, $A_{V}$ in Fig. 13 can buffer $v_{L}$ and LPF suppress noise components in $A_{V}$ 's impression of $i_{L}$ that are well above the system's $f_{\mathrm{SW}}$ to produce an observable output $\mathrm{v}_{\text {OUT. }} \mathrm{A}$ computer or a calibrating filter [15] can then divide $v_{\text {OUT }}$ by $\mathrm{L}_{\mathrm{X}}$ and $\mathrm{R}_{\mathrm{ESR}}$ 's combined impedance to reproduce $\mathrm{i}_{\mathrm{L}}$ in $\mathrm{i}_{\mathrm{S}}$.

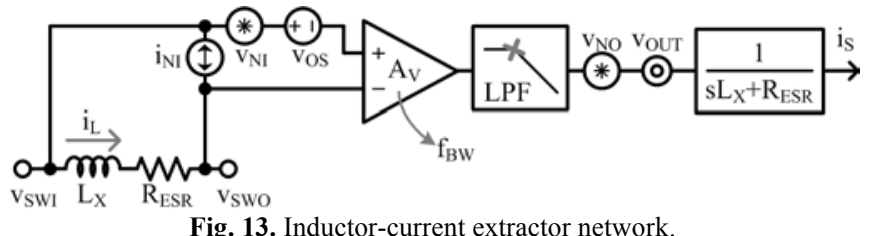

Thankfully, $v_{L}$ is in volts, so $A_{V}$ need not amplify $v_{L}$. As a result, $A_{V}$ 's bandwidth $f_{B W}$ can be high. Plus, with a gain of one, $A_{V}$ no longer amplifies the effects of input noise current and voltage $i_{\mathrm{NI}}$ and $\mathrm{v}_{\mathrm{NI}}$. And since $\mathrm{i}_{\mathrm{L}}$ and $\mathrm{i}_{\mathrm{NI}}$ drop a higher voltage across $L_{X}$ and $R_{E S R}$ than they would across $R_{S}$, the impact of $\mathrm{v}_{\mathrm{NI}}$ and $\mathrm{v}_{\mathrm{NO}}$ on $\mathrm{i}_{\mathrm{L}}$ diminishes:

$$
\mathrm{i}_{\mathrm{N}}=\sqrt{\mathrm{i}_{\mathrm{NI}}^{2}+\left(\frac{\mathrm{v}_{\mathrm{NI}}}{\mathrm{sL}_{\mathrm{X}}+\mathrm{R}_{\mathrm{ESR}}}\right)^{2}+\left[\frac{\mathrm{v}_{\mathrm{NO}}}{\mathrm{A}_{\mathrm{V}}\left(\mathrm{sL}_{\mathrm{X}}+\mathrm{R}_{\mathrm{ESR}}\right)}\right]^{2}} .
$$

In other words, signal-to-noise ratio $\mathrm{SNR}$ is nearly $40 \mathrm{~dB}$ at $100 \mathrm{kHz}$ in Fig. 14 and about $75 \mathrm{~dB}$ at $10 \mathrm{MHz}$.

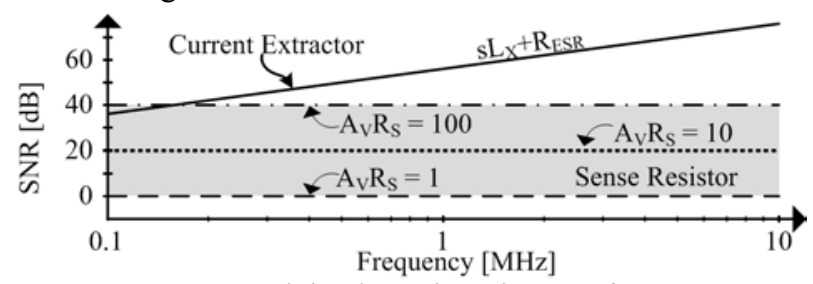

Fig. 14. Measured signal-to-noise ratio across frequency. 
Note that integrating $\mathrm{v}_{\mathrm{L}}$ across time only indicates how $\mathrm{i}_{\mathrm{L}}$ changes with time. In other words, to extract all components of $i_{L}$, this method requires $i_{L}$ 's initial value. If this initial value is unknown, $i_{S}$ and $i_{L}$ in Fig. 15 differ by an error $i_{\text {ERR }}$ :

$$
\mathrm{i}_{\text {ERR }}=\mathrm{i}_{\mathrm{S}}-\mathrm{i}_{\mathrm{L}}=\mathrm{I}_{\mathrm{ERR}(\mathrm{I})}\left[1-\mathrm{e}^{-\left(\frac{\mathrm{R}_{\mathrm{ESR}}}{\mathrm{L}_{\mathrm{X}}}\right) \mathrm{t}}\right] \text {, }
$$

where $\mathrm{I}_{\mathrm{ERR}(\mathrm{I})}$ is $\mathrm{i}_{\mathrm{S}}$ 's initial error. Luckily, $\mathrm{i}_{\mathrm{ERR}}$ eventually reduces to zero because $i_{L}$ 's average must ultimately match the current that $\mathrm{v}_{\mathrm{L}}$ 's average establishes across $\mathrm{R}_{\mathrm{ESR}}$. This is why $\mathrm{i}_{\mathrm{S}}$ is initially off by about $0.5 \mathrm{~mA}$ in Fig. 15 and within a few microamps of $i_{L}$ after $20 \mu \mathrm{s}$.

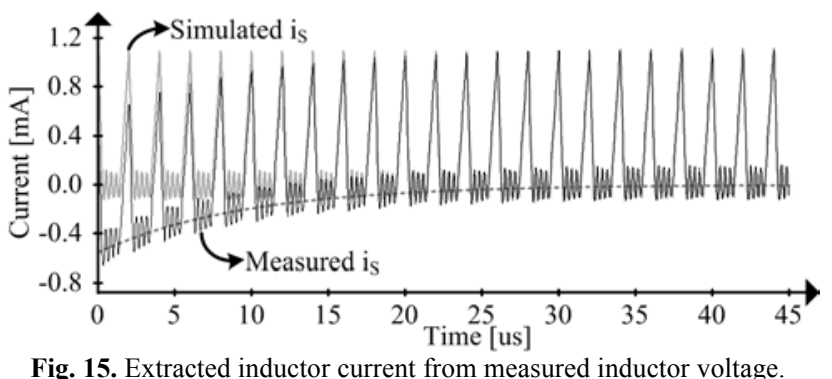

\section{COMPARISON OF MEASUREMENT TECHNIQUES}

Of the three methods, as Table I notes, only the coupled probe cannot monitor low-frequency components of the inductor current $i_{L}$. And the probe and sense resistor not only amplify input noise but also distort $i_{L}$, as Fig. 16 shows. In other words, extracting $i_{L}$ from measured inductor voltages is more complete, less noisy, and more linear. The only drawback to the extractor is the initial offset that eventually fades.

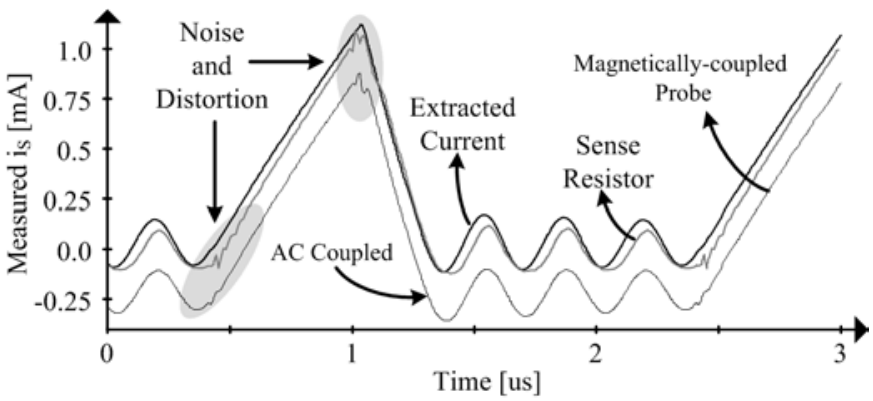

Fig. 16. Measured time-domain currents from all three methods.

Table I: COMPARISON OF MEASUREMENT TECHNIQUES

\begin{tabular}{|c|c|c|c|}
\hline & $\begin{array}{c}\text { Magnetically } \\
\text { Coupled Probe }\end{array}$ & $\begin{array}{c}\text { Sense } \\
\text { Resistor }\end{array}$ & $\begin{array}{c}\text { Current } \\
\text { Extractor }\end{array}$ \\
\hline $\begin{array}{c}\text { Components } \\
\text { Monitored }\end{array}$ & High Frequency & $\begin{array}{c}\text { Low and High } \\
\text { Frequency }\end{array}$ & $\begin{array}{c}\text { Low and High } \\
\text { Frequency }\end{array}$ \\
\hline $\begin{array}{c}\text { Noise in } \\
\text { Measurement }\end{array}$ & $\begin{array}{c}\mathrm{R}_{\mathrm{P}} \text { and } \mathrm{A}_{\mathrm{V}} \\
\text { Amplify Noise }\end{array}$ & $\begin{array}{c}\mathrm{R}_{\mathrm{S}} \text { and } \mathrm{A}_{\mathrm{V}} \\
\text { Amplify Noise }\end{array}$ & $\begin{array}{c}\text { No } \\
\text { Amplification }\end{array}$ \\
\hline Linearity & $\begin{array}{c}\text { Reflected } \mathrm{R}_{\mathrm{P}} \\
\text { Distorts } \mathrm{i}_{\mathrm{L}}\end{array}$ & $\mathrm{R}_{\mathrm{S}}$ Distorts $\mathrm{i}_{\mathrm{L}}$ & No Distortion \\
\hline
\end{tabular}

\section{CONCLUSIONS}

Measurements show that extracting micro-amp inductor currents in switching dc-dc converters from inductor voltages is more accurate, more linear, and less noisy than monitoring currents with a magnetic probe or a series sense resistor. In fact, distortion is negligible for the extractor and worst-case noise is on par with the resistor's best case in Fig. 14. The importance of these currents is that inductor current determines how well switched-inductor supplies operate. Evaluating this performance is imperative when considering the emerging ubiquity and benefits of wireless microsystems, whose tiny batteries exhaust quickly and supplies resort to switched inductors because they dissipate little power.

\section{ACKNOWLEDGMENT}

The authors thank Paul Emerson and Texas Instruments for supporting and sponsoring this research.

\section{REFERENCES}

[1] R. Vullers, et al., "Energy Harvesting for Autonomous Wireless Sensor Networks," IEEE Solid-State Circuits Magazine, vol. 2, pp 29-38, 2010.

[2] D. Puccinelli and M. Haenggi, "Wireless Sensor Networks: Applications and Challenges of Ubiquitous Sensing," IEEE Circuits and Systems Magazine, vol. 5, pp. 19-31, 2005.

[3] R.D. Prabha, and G.A. Rincon-Mora, "Harvesting Circuits for Minituarized Photovoltaic Cells," IEEE Int. Symp. on Circuits and Systems, pp.309-312, May 2011.

[4] K. Cheng, C.Su, and H. Ko, "A High-Accuracy and HighEfficiency On-chip Current Sensing for Current-Mode Control CMOS DC - DC Buck Converter," Int. Conf. on Electronics, Circuits and Systems, pp.458-461, Sep 2008.

[5] B. Yuan, and X. Lai, "On-Chip CMOS Current-sensing Circuit for DC-DC Buck Converter," Electronics Letters, vol. 45, pp 102-103, Jan 2009.

[6] S. Yuvaraian and L.Wang. "Power Conversion and Control using a current-sensing MOSFET," Midwest Symposium of Circuits and Systems, pp. 166-169, May 1991.

[7] J. Chen, et al., "Integrated Current Sensing Circuits Suitable for Step-down DC-DC Converters," Electroninc Letters, pp. 200202, Feb. 2004.

[8] N. Mohan, T. Undeland, and W. Robbins, Power Electronics Converters, Applications, and Design, $3^{\text {rd }}$ edn., John Wiley \& Sons, Inc., USA, 2003.

[9] H. Kim, M. Falahi T.M. Jahns, and M. Degner, "Inductor Current Measurement and Regulation Using a Single DC Link Current Sensor for Interleaved DC - DC Converters," IEEE Trans on Power Electronics, vol. 26, pp. 1503-1510, May 2011.

[10] S. Ang, and A. Olivia, Power-switching converters, $2^{\text {nd }}$ edn., Taylor \& Francis, USA, 2005.

[11] J. Sanchez-Moreno, et al., "Extending Magnetoresistive AC Transfer Characteristics for Current Measurement," Instrumentation and Measurement Technology Conf. pp. 305308, May 2008

[12] W. Huang, X. Yang, and C. Ling, "A novel current sensing Circuit for Boost DC - DC Converter," Anti-counterfeiting, Security and Identification Int. Conf., Aug 2012.

[13] A. Simon-Muerla, et al., "Practical Implementation of a HighFrequency Current-Sense Technique for VRM," IEEE Trans. On Industrial Electronics, vol. 55, pp. 3221-3230.

[14] C. Chang, "Lossless Current Sensing and Its Application in Current Mode Control," Power Electronics Specialists Conf. pp. 4086-4091, June 2008.

[15] H.P. Forghani-zadeh and G.A. Rincon-Mora, "An Accurate, Continuous, and Lossless Self-Learning CMOS Current-Sensing Scheme for Inductor-Based DC - DC Converters," IEEE J. of Solid-State Circuits, vol. 42, pp. 665-679, March 2007. 